NBER WORKING PAPER SERIES

\title{
TRANSITORY TERMS-OF-TRADE SHOCKS AND THE \\ CURRENT ACCOUNT: THE CASE OF \\ CONSTANT TIME PREFERENCE
}

Maurice Obstfeld

Working Paper No. $\underline{834}$

NATIONAL BUREATJ OF ECONOMIC RESEARCH 1050 Massachusetts Avenue

Cambridge MA 02138

January 1982

The research reported here is part of the NBER's research program in International Studies. Any opinions expressed are those of the author and not those of the National Bureau of Economic Research. 
Transitory Terms-of-Trade Shocks and the Current Account: The Case of Constant Time Preference

\begin{abstract}
$\underline{\text { Abstract }}$
The paper uses an intertemporal perfect-foresight optimizing model to analyze the effect of transitory terms-of-trade shocks on a small open economy's current-account and utility time profiles. An adverse terms-of-trade shift known to be temporary induces the economy to run down its stock of external assets in the period before the terms of trade revert to their initial level. Subsequently, the assets consumed during this period are reaccumulated. The current-account response is due only in part to a desire to smooth out the future consumption stream. In addition, households know that the real value of any debt incurred while the terms of trade are unfavorable will be reduced sharply when the terms of trade improve. This opportunity for intertemporal price speculation causes the time path of instantaneous utility to be discontinuous.
\end{abstract}

Maurice Obstfeld Department of Economics M.I.T. 50 Memorial Drive Cambridge, MA 02139

(January 1 - June 1, 1982) 
TRANSITORY TERMS-OF-TRADE SHOCKS AND THE CURRENT ACCOUNT: THE CASE OF CONSTANT TIME PREFERENCE

by

Maurice Obstfeld*

$\underline{\text { Introduction }}$

This paper employs a simple intertemporal optimization model to study the effects of transitory fluctuations in a small country's terms of trade. The paper's analysis centers on the current-account and utility paths induced by temporary terms-of-trade movements. An infinite planning horizon is postulated so that the long-run dynamic consequences of price disturbances may be pursued.

The results of transitory and anticipated terms-of-trade shocks have been analyzed in two-period models by Marion (1981), Sachs (1981), and Svensson and Razin (1981). - / As is illustrated below, however, extension of the analysis to an infinite-horizon setting leads to a richer description of the induced current-account paths. Obstfeld (1982) and Svensson and Razin (1981) have analyzed the effects of permanent unanticipated terms-of-trade changes using infinite horizon models that emphasize the role of subjective time preference in individual saving decisions. In contrast, the model explored below makes the simplifying assumption that the representative household's subjective time-preference rate is constant. $\underline{2}$ /

In the paper's mode1, a transitory worsening of the terms of trade causes a small open economy to run a current deficit. The current account moves into surplus when the terms of trade revert to their initial level, and the economy returns, in the long run, to its 
original level of external indebtedness. In the face of a permanent unanticipated terms-of-trade deterioration, however, agents cut their consumption by the full amount of the fall in their real income. No current imbalance ensues.

Although the current deficit induced by a transitory terms-oftrade setback is in part due to households' attempts to smooth their utility streams, the induced time profile of utility is not continuous. Because agents anticipate a decline in the real value of any external debt incurred while the terms of trade are poor, there is an additional incentive to shift consumption toward that period. The incentive disappears when the expected terms-of-trade improvement occurs, and so instantaneous utility falls discontinuously at that moment.

The paper is organized as follows. Section I describes the preferences and intertemporal substitution possibilities that form the building blocks of the model. Section II derives the conditions necessary for individual optimality -- the model's demand side. In section III we define the model's perfect-foresight equilibrium. Section IV studies the economy's dynamic response to a temporary adverse terms-of-trade shift, and section $V$ contains a detailed analysis of the utility path arising from this disturbance. Finally, section VI summarizes and concludes. 
I. The Model

The analysis concerns a small open economy consisting of identical, immortal households. Each of these planning units maximizes a welfare functional of the form

$$
V=\int_{0}^{\infty} u(x, m) \exp (-\delta t) d t
$$

The instantaneous utility function $u(\cdot, \cdot)$ appearing in ( 1 ) is defined over the household's consumption of a normal exportable good ( $x$ ) and a normal importable good (m). It is assumed that the utility function is strictly concave in its two arguments. $3 /$ is the representative household's constant (positive) rate of time preference. Each household is endowed with a flow of $y$ units of the perishable export good per unit time. The only available asset is an internationally-traded bond which carries a fixed face value equal to one unit of the importable good and entitles its owner to receive $r_{t}$ units of the importable per unit time. The time path of the interest rate $r_{t}$ will be determined within the model, as explained below. If $b_{t}$ denotes the number of bonds owned by a family at time $t$, saving (measured in terms of imports) is governed by the differential equation 4 /

$$
\dot{b}_{t}=\left(y / p_{t}\right)+r_{t} b_{t}-\left(x_{t} / p_{t}\right)-m_{t} .
$$

In (2), $p_{t}$ is the price of imports in terms of exports at $t$ ime $t$, the terms of trade. The representative household's bond stock at time $t=0$, $b_{0}$, is a predetermined variable given by the past history of asset 
accumulation. Any feasible consumption path must obey the intertemporal budget constraint

$$
\int_{0}^{\infty}\left[\left(x_{t} / p_{t}\right)+m_{t}\right] \exp \left[-\left(\int_{0}^{t} r_{s} d s\right)\right] d t \leq b_{0}+\int_{0}^{\infty}\left(y / p_{t}\right) \exp \left[-\left(\int_{0}^{t} r_{s} d s\right)\right] d t .
$$

of course, $b_{t}$ may assume negative values.

The time path of the terms of trade is parameterically given to the small country. In contrast, it is assumed that the interest rate at which the country can borrow in the world capital market is an increasing function of its aggregate net indebtedness. If the number of households is taken to be 1 for convenience, the equilibrium interest rate may be written as

$$
r_{t}=r\left(b_{t}\right)
$$

where $r^{\prime}\left(b_{t}\right)<0$.

Equation (4) embodies a departure from the customary assumption of a frictionless world capital market. The formulation reflects the difficulty many small countries encounter in obtaining foreign financing for external deficits. $5 /$ stability will require that interest income grow as net bond holdings grow. Accordingly, we assume that $-b r^{\prime}(b) / r<1$ for $a 11 b$.

\section{Individual Optima1ity}

The optimal plan of a household facing given time paths of the interest rate $r_{t}$ and terms of trade $p_{t}$ may be characterized by the maximum principle. $\underline{6}$ To apply that tool, we introduce the costate variable $\lambda_{t}$, which may be interpreted as the shadow price of bonds, In utility terms, at time $t$. According to the maximum principle, there is associated with an optimal consumption path $\left\{\mathrm{x}_{t}^{*}, \mathrm{~m}_{t}^{*}\right\}$ a costate variable path $\left\{_{\lambda_{t}}\right\}$ such that: (i) the Hamiltonian 
$\mathrm{H}_{t}=\left\{\mathrm{u}\left(\mathrm{x}_{\mathrm{t}}, \mathrm{m}_{\mathrm{t}}\right)+\lambda_{t}\left[\left(\mathrm{y} / \mathrm{p}_{\mathrm{t}}\right)+\mathrm{r}_{\mathrm{t}} \mathrm{b}_{\mathrm{t}}-\left(\mathrm{x}_{\mathrm{t}} / \mathrm{p}_{\mathrm{t}}\right)-\mathrm{m}_{\mathrm{t}}\right]\right\} \exp (-\delta \mathrm{t})$ is maximized with respect to $x_{t}$ and $m_{t}$ at $x_{t}=x_{t}^{*}, m_{t}=m_{t}{ }^{*}$; and (ii) $\lambda_{t}$ evolves according to the intertemporal arbitrage condition

$$
\frac{\dot{\lambda}_{\mathrm{t}}}{\lambda_{\mathrm{t}}}=\delta-\mathrm{r}_{\mathrm{t}}
$$

which states that the subjective time-preference rate $\delta$ must at each instant equal the physical return on bonds, $r_{t}$, plus the rate of "capital gain."

The necessary conditions for maximization of $\mathrm{H}_{t}$ (at an interior maximum) are: $:$ /

$$
\begin{aligned}
& u_{x}\left(x_{t}, m_{t}\right)-\lambda_{t} / p_{t}=0 \\
& u_{m}\left(x_{t}, m_{t}\right)-\lambda_{t}=0
\end{aligned}
$$

Together, (6) and (7) imply the familiar condition $u_{m}\left(x_{t}, m_{t}\right) / u_{x}\left(x_{t}, m_{t}\right)=p_{t}$, which allows us to write consumption of the importable as $m_{t}=\mu\left(x_{t}, p_{t}\right)$. Because both commodities are normal, $\mu_{x}=\left[\left(u_{x} u_{x m}-u_{m} u_{x x}\right) /\left(u_{m} u_{x m}-u_{x} u_{m m}\right)\right]$ $>0$ and $\mu_{\mathrm{p}}=\left[\mathrm{u}_{\mathrm{x}}{ }^{2} /\left(\mathrm{u}_{\mathrm{x}} \mathrm{u}_{\mathrm{mm}}-\mathrm{u}_{\mathrm{m}} \mathrm{u}_{\mathrm{xm}}\right)\right]<0$.

From (6), (7), and the definition of the function $\mu(\cdot, \cdot)$, an optimal consumption program has the form

$$
\begin{aligned}
& x_{t}=x\left(\lambda_{t}, p_{t}\right), \\
& m_{t}=\mu\left[x\left(\lambda_{t}, p_{t}\right), p_{t}\right] \equiv m\left(\lambda_{t}, p_{t}\right),
\end{aligned}
$$

where $\underline{8}$ /

$$
\begin{aligned}
& x_{\lambda}=\frac{u_{x}}{u_{m}\left(u_{x x}+u_{x m}{ }^{\mu}\right)}=\frac{u_{x} u_{m m}-u_{m} u_{x m}}{u_{m}\left[u_{x x} u_{m m}^{-}\left(u_{x m}\right)^{2}\right]}<0, \\
& x_{p}=-\frac{u_{x} 2+u_{m} u_{x m}^{\mu} p}{u_{m}\left(u_{x x}+u_{x m}{ }^{\mu}\right)}=\frac{-u_{x}{ }^{2} u_{m m}}{u_{m}\left[u_{x x} u_{m m}-\left(u_{x m}\right)^{2}\right]}>0,
\end{aligned}
$$




$$
\begin{aligned}
& m_{\lambda}=\mu_{x} x_{\lambda}=\frac{u_{m} u_{x x}-u_{x} u_{x m}}{u_{m}\left[u_{x x} u_{m m}-\left(u_{x m}\right)^{2}\right]}<0, \\
& m_{p}=\mu_{x} x_{p}+\mu_{p}=\frac{u_{x}^{2} u_{x m}}{u_{m}\left[u_{x x} u_{m m}-\left(u_{x m}\right)^{2}\right]}<0 .
\end{aligned}
$$

Given an initial value $\lambda_{0}$ of the costate variable, $\lambda_{t}$ is given, according to (5), by $\lambda_{t}=\lambda_{0} \exp \left[\int_{t}^{t}\left(\delta-r_{s}\right) d s\right]$, while $b_{t}$ may be written

$$
b_{t}=b_{0} \exp \left(\int_{0}^{t} r_{s} d s\right)+\int_{0}^{t}\left[\left\{\left(y / p_{s}\right)-\left[x\left(\lambda_{s}, p_{s}\right) / p_{s}\right]-m\left(\lambda_{s}, p_{s}\right)\right] \exp \left(\int_{s}^{t} r_{\tau} d \tau\right)\right] d s .
$$

Thus, given $b_{0}$, an initial choice of $\lambda_{0}$ determines the subsequent paths of consumption and bond holdings.

Although an optimal 1ifetime program must be determined in the foregoing manner, not every choice of $\lambda_{0}$ results in an optimal plan. Conditions (5), (8), and (9), while necessary for optimality, are not, in general, sufficient. We return to this point in the next section.

\section{Perfect-Foresight Equilibrium}

The previous section described how the household must plan its consumption given an arbitrary path $\left\{x_{t}\right\}$ of the real interest rate. By (4), however, $r_{t}$ is affected by household choices. To close the model, we

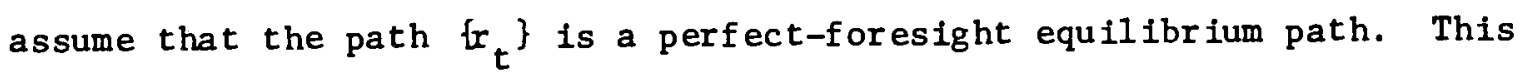
means that when households formulate their preferred consumption plan in the belief that $r_{t}$ will prevail at date $t$, the Implied optimal path of bond holdings, $\left\{b_{t}^{*}\right\}$ satisfies the relation $r_{t}=r\left(b_{t}^{*}\right)$, for all $t .9 /$

The paths of $\lambda_{t}$ and $b_{t}$ satisfying both the necessary conditions for Individual optimality and the perfect-foresight requirement are described by the differential equations

$$
\begin{aligned}
& \dot{\lambda}_{t}=\lambda_{t}\left[\delta-r\left(b_{t}\right)\right], \\
& \dot{b}_{t}=\left(y / p_{t}\right)+r\left(b_{t}\right) b_{t}-\left[x\left(\lambda_{t}, p_{t}\right) / p_{t}\right]-m\left(\lambda_{t}, p_{t}\right) .
\end{aligned}
$$


Equations (10) and (11) are derived from (2) and (5) by substituting (4), (8), and (9). Equation (10) describes the necessary arbitrage relationship linking the equilibrium real interest rate, the time preference rate, and the rate of shadow capital gain. Equation (11) describes the equilibrium current-account balance. The sole forcing variable in (11) is the contemporaneous terms of trade $\mathrm{p}_{t}$. This fact will prove useful below.

The temporary assumption that $p_{t}$ is expected to be constant at $\bar{p}$ at all dates leads to a useful diagrammatic representation of the dynamic system described by (10) and (11). Figure 1 displays this representation. The $\dot{\lambda}=0$ locus is vertical at the unique level of external assets $\bar{b}$ bringing the interest rate into equality with the subjective discount rate $\delta$. To the right of the $\dot{\lambda}=0$ locus, $r(b)<\delta=r(\bar{b})$ by $(4)$, and $\lambda$ is increasing; to the left of this locus, $\lambda$ is decreasing. Current-account balance obtains along the $\dot{b}=0$ locus. Its slope is negative under the earlier stability assumption, and is given by

$$
\left.\frac{d \lambda}{d b}\right|_{b=0}=\frac{r\left[\left(b r^{\prime}(b) / r\right)+1\right]}{\left(x_{\lambda} / \bar{p}\right)+m_{\lambda}} .
$$

To the right of the external-balance locus, the current account is in surplus, while to its left, the current account is in deficit. The phase portrait indicates that the system is saddlepoint-stable, with a unique path SS converging to its stationary position $(\bar{b}, \bar{\lambda}) . \underline{10 /}$ Moreover, for any initial bond stock $b_{0}$, the saddlepath SS describes the unique initial costate value $\lambda_{0}$ associated with an equilibrium path. Thus, when no future changes in the terms of trade are expected, the equilibrium of the economy will always be on the saddlepath. 


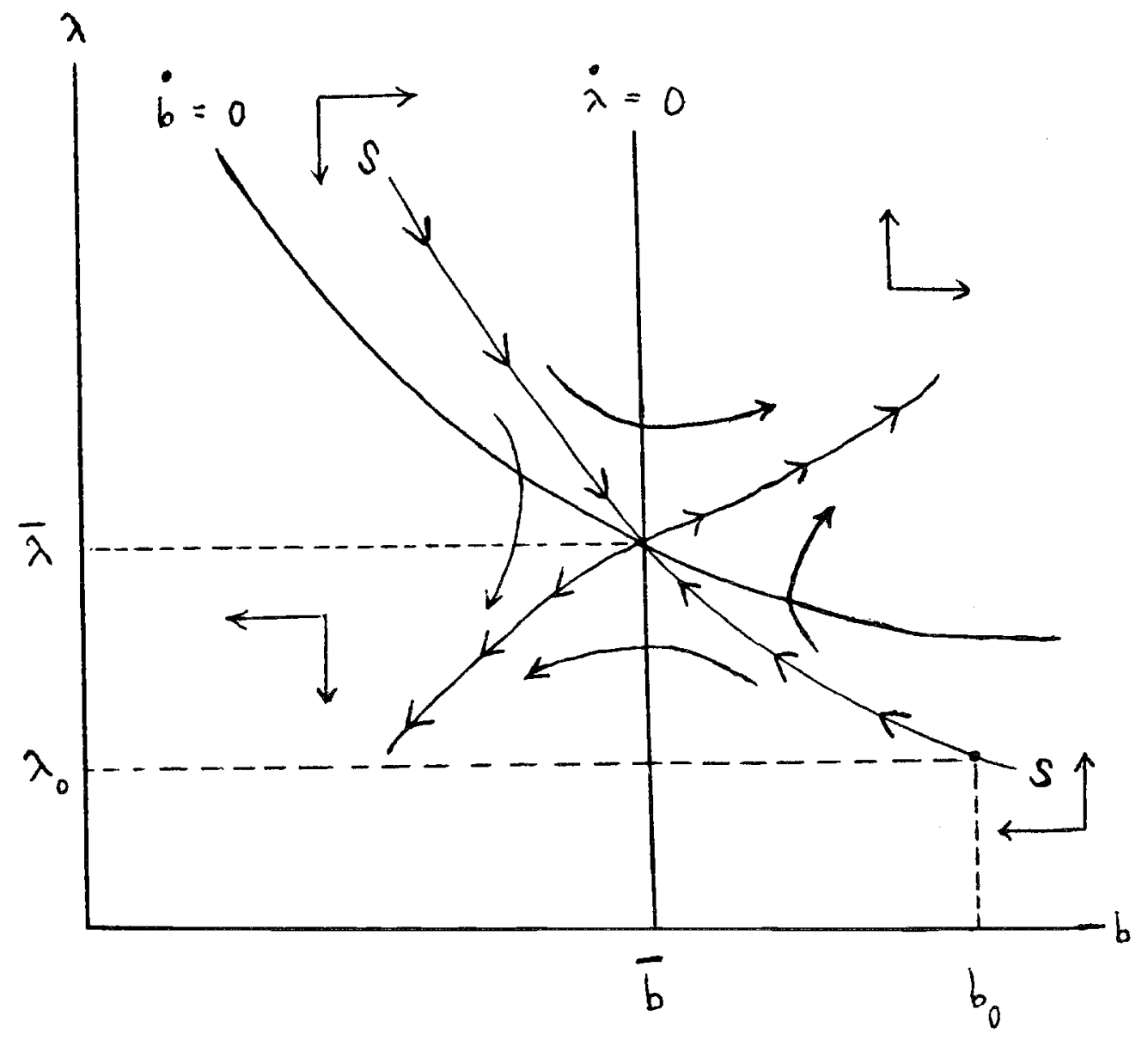

Figure 1 
We can demonstrate the existence and uniqueness of perfectforesight equilibrium as follows. Let $b_{0}$ be the predetermined initial bond stock and consider the convergent trajectory originating at the costate value $\lambda_{0}$. To show that the latter is an equilibrium path (thereby establishing existence), we must show that when the household expects the associated interest-rate path, the optimal path of bond holdings generates those interest rates. However, this follows from the transversality condition

$$
\lim _{t \rightarrow \infty} \lambda_{t} b_{t} \exp (-\delta t)=0
$$

which is sufficient for individual optimality (see Arrow and Kurz (1970), p. 49).11/ To show uniqueness, we argue that no other choice of $\lambda_{0}$ produces an equilibrium path. Paths originating below ss are infeasible, for they lead to unbounded external indebtedness and therefore violate the budget constraint (3). Because $x_{\lambda}, m_{\lambda}<0$, paths originating above sS lead to ever-falling consumption coupled with ever-rising income. These "over-accumulation" paths are clearly nonoptimal from the household's point of view, and, like the infeasible paths, may be ruled out as possible equilibria.

It is now assumed that along the economy's equilibrium path,

$$
m_{t}>r\left(b_{t}\right) b_{t}
$$

Inequality (12) ensures that the economy always remains a net importer of the importable good. 


\section{Transitory Terms-of-Trade Shocks}

Before turning to the analysis of temporary terms-of-trade movements, it is convenient to use the previous section's diagrammatic apparatus to analyze a permanent and unanticipated increase in the relative price of imports from $\overline{\mathrm{p}}$ to $\overline{\mathrm{p}}^{\prime}$. The economy is assumed to be fnitially at the long-run equilibrium $(\bar{\zeta}, \bar{\lambda})$.

The long-run bond level remains at $\bar{b}$ in the face of this shock, for long-run equilibrium requires that $\delta=r(\bar{b})$. However, because

$$
\frac{d \bar{\lambda}}{d p}=-\frac{[\bar{m}-r(\bar{b}) \bar{b}]-\bar{x}_{\lambda} \bar{u}_{x}}{\bar{x}_{\lambda}+p \bar{m}_{\lambda}}
$$

is positive by (12), the long-run shadow price of external assets, $\bar{\lambda}$, rises to $\bar{\lambda}^{\prime}$ as shown in Figure 2. Thus, while the $\dot{\lambda}=0$ locus is unaltered, the externalbalance locus shifts to $\dot{b}^{\prime}=0$. Because the economy's bond holdings are already at their new stationary level, $\lambda$ jumps on impact to $\bar{\lambda}^{\prime}$ and no currentaccount disequilibrium ensues. Under the assumption that the subjective time-preference rate is constant, a permanent fall in real income elicits an equal cut in spending. $\frac{12 /}{}$

Consider now the consequences of a transitory worsening in the terms of trade (from $\overline{\mathrm{p}}$ to $\overline{\mathrm{p}}^{\prime}$ ), one which agents expect to be reversed at time $\mathrm{T}$ in the future. $13 /$ The current-account path occasioned by this disturbance can be visualized with the aid of Figure 2 .

Equations (10) and (11) imply that between times $t=0$ and $t=T$, the economy must be on a path of the system associated with terms of trade $\bar{p}^{\prime}$. They also imply that after time $T$, the economy must be on a path of the system associated with terms of trade $\bar{p}$. Indeed, because the terms of 
trade are expected to remain at $\bar{p}$ after time $T$ and the household's plan must be optimal from time $T$ onward (by Bellman's principle), the economy must be on the convergent path SS for $t \geq T$. This follows from the previous section's result that SS defines the unique equilibrium for the economy when the terms of trade are expected to remain at $\bar{p}$ forever.

Since the level $\bar{b}$ of the stock of external assets is predetermined at $t=0$, one additional initial condition is needed to identify the economy's path. The required condition comes from observing that the shadow price $\lambda_{t}$ cannot take a discrete jump at time $T$, but must instead follow a continuous path. This type of asset-price continuity condition is familiar from the monetary rational-expectations literature (see Calvo 1977) and is applicable in the present setting as well. A discrete anticipated jump in $\lambda_{t}$ would violate the intertemporal arbitrage condition $\delta=\left(\dot{\lambda}_{t} / \lambda_{t}\right)+r_{t}$, and is therefore inadmissible along a perfect-foresight equilibrium path. $14 /$

The implied path of the economy is depicted in Figure 2. When the terms of trade initially deteriorate to $\bar{p}^{\prime}$, the economy moves to $E_{0}$ and the current account swings into deficit. Households continue to borrow until time $T$, when the terms of trade return to $\bar{p}$. At $E_{T}$, the current account goes into surplus as the economy begins to repay the debt incurred during the temporary fall in real income. Asymptotically, the initial equilibrium $(\bar{b}, \bar{\lambda})$ is regained.

Although a permanent adverse terms-of-trade shift evokes no currentaccount response, an adverse shift known to be temporary induces the household to rearrange its utility stream. By running down external assets 


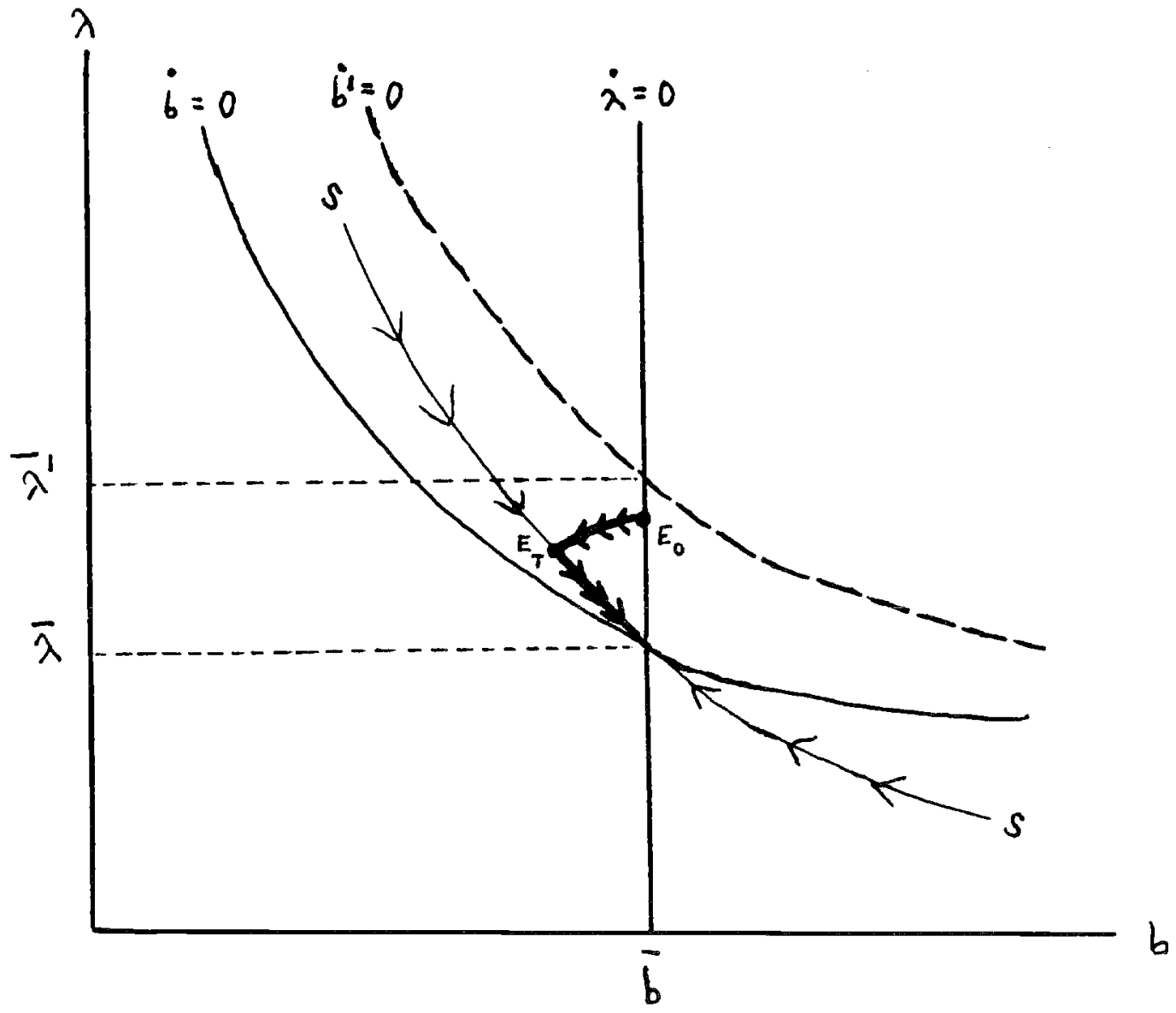

Figure 2 
while times are bad and reaccumulating these assets after the terms of trade have improved, the household softens the immediate impact of the shock at the cost of reducing consumption after $\mathrm{T}$ below the level that would have been feasible if no current deficit had been run. In this sense, the household smooths its consumption path.

A transitory terms-of-trade shift from $\bar{p}$ to $\bar{p}$ ' may be viewed alternatively as a permanent shift to $\bar{p}^{\prime}$ together with an anticipated future shift to $\bar{p}$. In response to a permanent terms-of-trade deterioration, the economy would, as we have seen, jump to $\left(\bar{b}^{\prime}, \bar{\lambda}^{\prime}\right)$. But the anticipation of a relative-price improvement induces the economy to raise its expenditure beyond its income immediately and thus run a deficit until the expected event accurs at time $\mathrm{T}$.

The longer the duration of the terms-of-trade shock, the closer it is to being permanent. Thus, as $T \rightarrow \infty, E_{0}$ moves monotonically upward toward the point $\left(\bar{b}^{\prime}, \bar{\lambda}^{\prime}\right)$.

\section{The Time Profile of Utility}

A detailed discussion of the time path of instantaneous utility throws additional light on the equilibrium response to a transitory termsof-trade movement. In particular, we learn that individual optimality involves an element of intertemporal price speculation which causes a discontinuity in the time profile of utility.

From (8) and (9), time-t utility is given by

$$
u_{t}=u\left[x\left(\lambda_{t}, p_{t}\right), m\left(\lambda_{t}, p_{t}\right)\right] \text {. }
$$

Expression (14) may be used in conjunction with Figure 2 to determine the rate of change of utility along the economy's equilibrium path. Between $\mathrm{t}=0$ and $\mathrm{t}=\mathrm{T}, \dot{\lambda}_{\mathrm{t}}<0$, and because $\mathrm{x}_{\lambda}, \mathrm{m}_{\lambda}<0$ and $\mathrm{p}_{\mathrm{t}}$ is constant at $\overline{\mathrm{p}}^{\prime}$ until 
time $T, u_{t}$ must be rising. For the same reason $u_{t}$ grows forever after time $\mathrm{t}=\mathrm{T}$. Since the economy regains its pre-disturbance utility level $\bar{u}$ in the long run, $u_{t}<\bar{u}$ for $t \geq T$.

What happens to utility at time T? The terms of trade return to $\bar{p}$ from $\bar{p}^{\prime}$, but the costate does not jump. Because, by (14),

$$
\left.\frac{d u}{d p}\right|_{\lambda=\lambda_{T}}=u_{x} x_{p}+u_{m} m_{p}=-\left(u_{x}\right)^{2} x_{\lambda}>0,
$$

utility falls abruptly when the terms of trade improve at time $T$. There is therefore a discontinuity in the instantaneous utility path at that point. Figure 3 displays one possible utility time path.

This discontinuity in the utility time profile requires comment. If relative prices were unalterably fixed but domestic output $y$ were to fall temporarily, the economy's current-account path would be qualitarively similar to the one shown in Figure 2. But with constant terms of trade, the continuity of $\lambda_{t}$ would imply a continuous path for $u_{t}$ as well: Utility would therefore fall initially, and then rise continuously toward its asymptotic level. In the present context of price variability, however, continuity of $u_{m}\left(x_{t}, m_{t}\right)$ (cf.equation ( 7$)$ ) does not imply continuity of $u_{t}$.

As was suggested in section IV, the economy's reaction to a temporary terms-of-trade deterioration arises in part from a desire to smooth the feasible utility stream. But because a relative price change is anticipated, an element of intertemporal price speculation enters the household's calculations as well. This explains the discontinuity in the utility profile. The fall in permanent income caused by the temporary price setback induces households to cut their absorption. But they know, in addition, that the

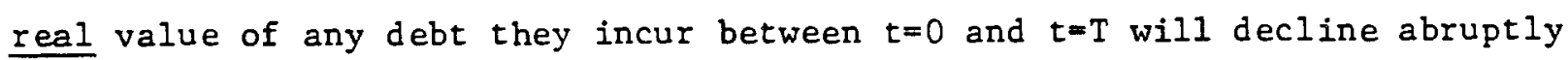
when $\bar{p}^{\prime}$ falls to $\bar{p} \cdot \frac{15 /}{}$ This expectation irduces them to increase their consumption 


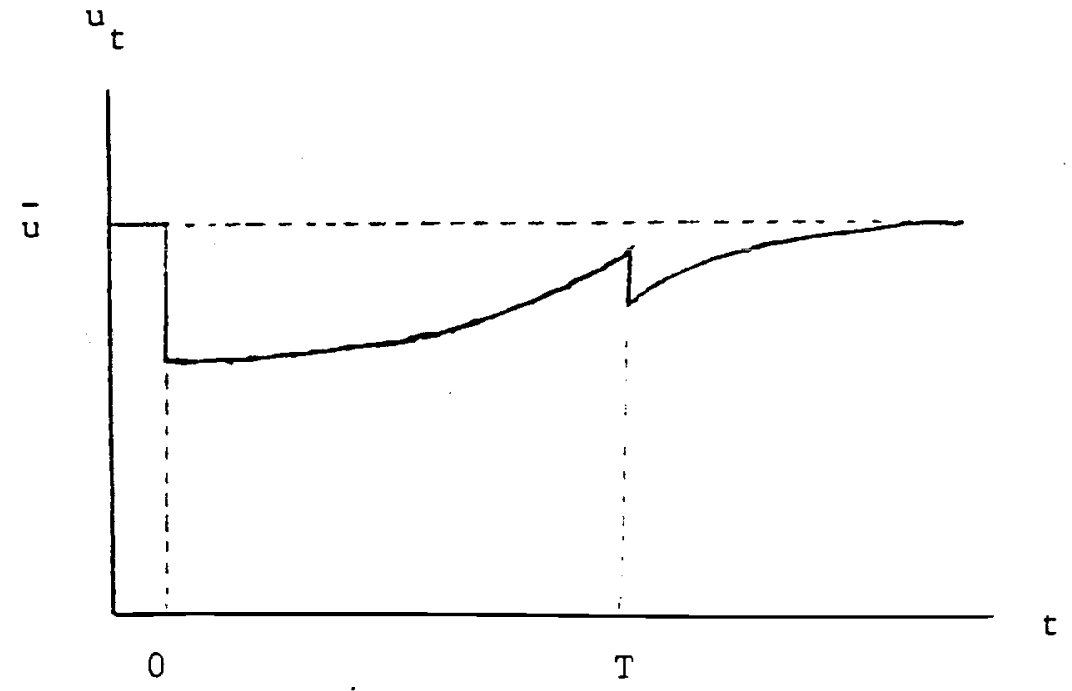

Figure 3 
while the terms of trade are unfavorable and reduce consumption sharply the moment the anticipated capital gains have been realized.

\section{Conclusion}

This paper has studied the effects of transitory terms-of-trade fluctuations on a small open economy. Using a simple intertemporal optimizing model of individual behavior, the paper showed that a temporary worsening in the terms-of-trade occasions a current-account deficit which lasts until the terms of trade return to their initial level. Subsequently, the economy travels back to its original position.

While this current-account path is explicable in part by households' desire to smooth their utility streams, the economy's utility time profile is in fact discontinuous. What lies behind this result is the anticinated reduction in the real value of any foreign debt incurred while the terms of trade are unfavorable.

Two directions for further study are apparent. First, the assumption of a constant subjective time-preference rate should be relaxed along lines suggested by obstfeld (1982) and Svensson and Razin (1981). Second, the connections between the terms of trade and domestic profitability and capital accumulation should be explored. Only by synthesizing the theories of investment and saving in an open-economy setting can we obtain a complete and convincing theory of the current account. 


\section{Notes}

* This paper was written while the author was a visitor in the International Finance Division of the Board of Governors of the Federal Reserve System. Partial financial support from the National Science Foundation is acknowledged with thanks. This paper represents the views of its author and should not be interpreted as reflecting the views of the Board of Governors of the Federal Reserve System or members of its staff.

1. Dornbusch and Krugman (1976) emphasize the distinction between permanent and transitory changes in an informal discussion of the current-account effects of relative-price shocks.

2. Dornbusch (1981) uses a similar model of the household to analyze the response to output and real interest rate fluctuations of a small open economy producing tradable and non-traded goods.

3. The concavity condition is that $u_{x x}<0, u_{m m}<0$, and $u_{x x} u_{m m}-\left(u_{x m}\right)^{2}>0$. Normality of $x$ implies that $u_{x} u_{m m}-u_{m} u_{x m}<0$. Normality of $m$ implies that $u_{x} u_{x m}-u_{m} u_{x x}>0$. It is assumed in addition that the utility function obeys the regularity conditions:

$\lim _{x \rightarrow 0} u_{x}(x, m)=\infty, \quad \lim _{x \rightarrow \infty} u_{x}(x, m)=0, \lim _{m \rightarrow 0} u_{m}(x, m)=\infty, \lim _{m \rightarrow \infty} u_{m}(x, m)=0$.

4. While $b_{t}$ is a continuous function of time, it need not be differentiable-the current-account balance $\dot{b}_{t}$ can change sharply. At points where $b_{t}$ has no derivative, equation (2) below is interpreted as giving the right-hand derivative of $b_{t}$. 
5. Hamada (1969) uses a similar formulation in a model with domestic investment. It is plausible that the schedule $r(b)$ will be relatively steep when $b<0$ and relatively flat when $b>0$. The technical convenience afforded by the assumption of a variable bond rate is that it ensures the existence of a stationary long-run equilibrium for the economy.

6. See Arrow and Kurz (1970).

7. Below, subscripts, with the exception of time subscripts ( $t, s, \tau)$, denote partial derivatives. Thus, $u_{x} \equiv \partial u / \partial x$, etc.

8. The inequalities below follow from the assumptions of concavity and normality (cf. note 3 , above).

9. Because households behave competitively, the interest rate $r_{t}$ they perceive differs from the economy's true marginal borrowing cost. This type of distortion is familiar from the optimal tariff literature.

10. Here and below, overbars denote stationary-state values.

11. Strictly speaking, the theorem cited here requires that $b_{t} \geq 0$ for all $t$. However, $b_{t}$ is certainly bounded below, for it must be the case that $y+\overline{p r}\left(b_{t}\right) b_{t} \geq 0$ for all $t$ if the intertemporal budget constraint (3) is to be satisfied at the household level. As shown in obstfeld (1981), the transversality condition remains sufficient for optimality when the state variable is bounded below. 
12. This result would not necessarily hold if the time-preference rate were endogenous. In the setup of Obstfeld (1982), where the time preference rate is an increasing function of current instantaneous utility, a permanent unanticipated fall in real income occasions a current-account surplus.

13. By assumption, the transitory terms-of-trade change is itself unanticipated.

14. Hall (1978) makes use of the stochastic discrete-time analogue of this condition to test the permanent income hypothesis in a one-good setting. The proposition he tests is that the marginal utility of consumption follows a random walk with trend. Abel and Blanchard (1980), in a closed-economy saving-investment model, also use the continuity condition invoked in the text. While the path $\lambda_{t}$ must be continuous, it need not be differentiable. The time derivative $\dot{\lambda}_{t}$ appearing in the intertemporal arbitrage relationship should be interpreted as the right-hand derivative of $\lambda_{t}$.

15. Recall that bonds have a face value fixed in terms of the importable. Thus, an improvement in the home country's terms of trade lowers the value of a.bond when this is expressed in terms of a basket including both importables and exportables. 


\section{$\underline{\text { References }}$}

Abel, Andrew B., and Blanchard, Olivier J. "An Intertemporal Equilibrium Model of Saving and Investment." Mimeo, Department of Economics, Harvard University, 1980.

Arrow, Kenneth J., and Kurz, Mordecai. Public Investment, the Rate of Return, and Optimal Fiscal Policy. Baltimore: The Johns Hopkins Press, 1970.

Calvo, Guillermo A. "The Stability of Models of Money and Perfect Foresight: A Note," Econometrica 45 (October 1977): 1737-9.

Dornbusch, Rudiger. "Real Interest Rates, Home Goods and Optimal External Borrowing." Mimeo, Department of Economics, Massachusetts Institute of Technology, 1981 .

Dornbusch, Rudiger, and Krugman, Paul. "Flexible Exchange Rates in the Short Run," Brookings Papers on Economic Activity 7 (1976): 537-75.

Hall, Robert E. "Stochastic Implications of the Life Cycle-Permanent Income Hypothesis: Theory and Evidence," Journal of Political Economy 86 (December 1978): 971-87.

Hamada, Koichi. "Optimal Capital Accumulation by an Economy Facing an International Capital Market," Journal of Political Economy 77 (July/August 1969): 684-97.

Marion, Nancy P. "Anticipated and Unanticipated Oil Price Increases and the Current Account." Working Paper no. 759, National Bureau of Economic Research, Cambridge, Massachusetts, 1981.

Obstfeld, Maurice. "Macroeconomic Policy, Exchange-Rate Dynamics, and Optimal Asset Accumulation," Journal of Political Economy 89 (December 1981): $1142-61$. 
Obstfeld, Maurice. "Aggregate Spending and the Terms of Trade: Is there a Laursen-Metzler Effect?" Quarterly Journal of Economics 9-7 (1982), in press.

Sachs, Jeffrey D. "The Current Account and Macroeconomic Adjustment in the 1970s," Brookings Papers on Economic Activity 12 (1981): 201-68.

Svensson, Lars E. O., and Razin, Assaf. "The Terms of Trade, Spending and the Current Account: The Harberger-Laursen-Metzler Effect." Seminar Paper no. 170, Institute for International Economic Studies, University of Stockholm, 1981 . 